\title{
INDICATIVOS PARA IMPLANTAÇÃO DE UMA FEIRA ORGÂNICA EM CAMAQUÃ/RS
}

\author{
Fabíola Borges Kramer Weege \\ Universidade Federal de Pelotas \\ bibes_kramer@hotmail.com \\ Sônia Teresinha DeNEGRI \\ Universidade Federal de Pelotas \\ soniadn15@gmail.com
}

\begin{abstract}
Resumo
Esta pesquisa objetivou identificar a viabilidade de implantação de feira de alimentos orgânicos, na cidade de Camaquã/RS. Realizaram-se entrevistas com questões semiestruturadas junto aos produtores/feirantes da Feira do Produtor Rural Willi Dummer, tradicional na cidade. O gestor municipal na prefeitura também foi entrevistado. A feira ocorre duas vezes por semana, com produtos oriundos da agricultura convencional, tais como frutas, verduras e leguminosas. O município apresenta capacidade produtiva para agricultura familiar. Os participantes manifestaram interesse em cultivar alimentos de natureza agroecológica e apoiam a organização de uma feira de orgânicos. Na atualidade, a implantação de uma feira de orgânicos em Camaquã/RS não seria realizável. Ocorre necessidade de estímulos à produção local de orgânicos e incentivos pelo poder público. Aos agricultores devem ser oferecidas informações técnicas e capacitação sobre métodos produtivos para orgânicos, sendo a participação do gestor municipal importante para as mudanças na agricultura local. Palavras-chave: Alimentos Orgânicos. Agricultura Sustentável. Cultivos Agrícolas. Feira Orgânica.
\end{abstract}

\section{INDICATIVES FOR IMPLANTATION OF ORGANIC FAIR IN CAMAQUÃ/RS}

\begin{abstract}
The objective of this research was to identify the viability of an organic food fair in the city of Camaquã/RS. Semistructured interviews were held with the producers / tradesmen of the Willi Dummer Rural Producer Fair, which is traditional in the city. The municipal manager (City Hall) was also interviewed. The fair occurs twice a week, with products from conventional agriculture, such as fruits, vegetables and vegetables. The municipality has a productive capacity for family agriculture. Participants expressed interest in growing food of an agroecological nature and support the organization of an organic fair. At the present time, the implantation of an organic fair in Camaquã/RS would not be feasible. There is a need for incentives for local organic production and incentives for the public authorities. To the farmers, technical information and training on productive methods for organic food should be offered, with the local government as an important factor for the agriculture`s changes.

Keywords: Organic Food. Sustainable Agriculture. Agricultural Crops. Organic Fair.

\section{INDICATIVOS PARA LA IMPLANTACIÓN DE UNA FERIA ORGÁNICA EN CAMAQUÃ/RS}

\section{Resumen}

Esta investigación objetivó identificar la viabilidad de implantación de la feria de alimentos orgánicos en la ciudad de Camaquã /RS. Se realizaron entrevistas con cuestiones semiestructuradas entre los productores/feriantes de la Feria del Productor Rural Willi Dummer, tradicional en la ciudad. El administrador municipal (Ayuntamiento) también fue entrevistado. La feria se produce dos veces por semana, con productos oriundos de la agricultura convencional, tales como frutas, verduras y leguminosas. El municipio presenta capacidad productiva para agricultura familiar. Los participantes manifestaron interés en cultivar alimentos de naturaleza agroecológica y apoyan la organización de una feria de orgánicos. En la actualidad, la implantación de una feria de orgánicos en Camaquã/RS no sería realizable. Se requiere de estímulos a la producción local de orgánicos e incentivos por el poder público. A los agricultores deben ser ofrecidas informaciones técnicas y capacitación sobre métodos productivos para orgánicos, siendo la participación del gestor municipal importante para los cambios en la agricultura local.

Palabras clave: Alimentos Orgánicos. Agricultura Sostenible. Cultivos Agrícolas. Feria Orgánica. 


\section{INTRODUÇÃO}

Camaquã é município do estado do Rio Grande do Sul, faz parte da Região Centro-Sul e, dista a $127 \mathrm{~km}$ da capital, Porto Alegre (CAMAQUÃ, 2016). Segundo dados do Instituto Brasileiro de Geografia e Estatística (IBGE), o município possui área territorial de 1.679,434km², sendo 22\% em área rural. E, consta população de 62.724 habitantes (INSTITUTO..., 2006). Originalmente o município era dividido em 11 distritos, sendo que três foram emancipados. Atualmente a cidade é formada pelos distritos de Camaquã, Bonito, Capela Velha, Pacheca, Santa Auta, Capela Santo Antônio, Banhado do Colégio e Bandeirinha.

Camaquã tem sua economia baseada na produção agropecuária, com ênfase na orizicultura que é sua principal fonte de renda, sendo considerada a "capital nacional do arroz parboilizado". O fumo, a soja e o milho são outras importantes culturas. A indústria dominante serve ao beneficiamento de arroz, sendo que o comércio, atuante e diversificado, também contribui na economia do município (CAMAQUÃ, 2016).

A produção alimentícia do município corresponde com a vocação agropecuária da região. Uma das formas de comercialização da produção agrícola familiar ocorre através de feira do produtor rural, em atividade há quase duas décadas, organizada às quartas-feiras e aos sábados, no turno matutino, na sede da "Feira do Produtor Rural Willi Dummer". São comercializados produtos resultantes da agricultura convencional, predominando as frutas, verduras e leguminosas. Também são comercializados produtos alimentícios caseiros, carnes, embutidos e queijos (CAMAQUÃ, 2016).

A agricultura convencional se realiza sob influência do que foi difundido por ocasião da revolução verde na década de 1970, em que o avanço da produção agrícola foi impulsionado pela mecanização da agricultura e adoção de agroquímicos, nas lavouras. Com o passar dos anos surgiram incrementos tecnológicos em genética vegetal, acompanhando os interesses para maior produtividade e lucratividade (ALMEIDA, 2002; NIEDERLE; ALMEIDA; VEZZANI, 2013). $\mathrm{Na}$ atualidade, o Brasil apresenta-se problematizado pelo elevadíssimo uso de agrotóxicos na agricultura, sendo que as plantas, o solo e a água passam a ser contaminados por esses produtos químicos (RIGOTTO et al., 2012).

A agricultura ecológica, cuja premissa é a utilização de métodos e técnicas que respeitem os limites e as potencialidades da natureza para produção agrícola, ainda é pouco expressiva no Brasil (LOURENÇO; SCHNEIDER; GAZOLLA, 2017). A agroecologia refere-se aos agroecossistemas, onde se encontram o ambiente e os elementos humanos em processos interativos, com foco na produção e promoção da sustentabilidade, com menor impacto 
Indicativos para implantação de uma feira orgânica em Camaquã/RS

ambiental e social (ALTIERI, 1995 apud ALTIERI; NICLHOLLS, 2005). Através da prática de agroecologia valorizam-se as trocas de saberes científicos com os saberes locais, desenvolvidos pelos agricultores (CAPORAL; COSTABEBER, 2004).

Em sistemas sustentáveis, ocorre a intenção de gerar qualidade de vida humana, tanto para o agricultor por abster-se do uso de agrotóxicos e evitar contaminação pessoal, como para o consumidor ao acessar um alimento saudável (AZEVEDO; PELICIONI, 2011).

A promoção de Segurança Alimentar e Nutricional (SAN) da população implica, também, na luta pelo acesso a alimentos adequados e saudáveis, livres de agrotóxicos e nãotransgênicos (RIGOTTO et al., 2012).

Alimentos orgânicos são definidos como aqueles in natura ou processados oriundos de sistema orgânico de produção agroecológica. Este tipo de produção é baseado em técnicas que dispensam o uso de qualquer insumo ou aditivo sintético, irradiação e não aceitam organismos geneticamente modificados. A ênfase da produção está direcionada para práticas de gestão e de manejo do solo, segundo as condições regionais e a necessidade de adaptar localmente os sistemas de produção (FOOD AND AGRICULTURE ORGANIZATION, 1999).

Em relação ao valor nutricional, os alimentos orgânicos podem contribuir para a promoção e a preservação da saúde humana. Comparados aos alimentos de cultivo convencional tendem a ser mais saborosos, a conterem mais vitamina $\mathrm{C}$ e compostos fenólicos, com menor teor de água (LIMA, 2006).

A garantia de que o alimento foi produzido de forma orgânica, no Brasil, ocorre a partir de mecanismos de controle social. Os mecanismos de Certificação por Auditoria e Certificação por Sistemas Participativos de Garantia seguem as normas do Sistema Brasileiro de Avaliação da Conformidade Orgânica (SISORG). Outra modalidade de controle ocorre pelo dito Controle Social, quando o agricultor familiar é cadastrado em órgão fiscalizador oficial e a venda da sua produção não requer obrigatoriedade de certificação. Nesta modalidade, a venda ocorre diretamente ao consumidor ou para programas de compras públicas de alimentos da agricultura familiar (BRASIL, 2009).

Azevedo (2006) destaca as variantes envolvidas no processo produtivo dos alimentos e o custo dos alimentos orgânicos, podendo o preço apresentar variação de $20 \%$ a $100 \%$ a mais em relação aos alimentos de origem convencional. A lei da oferta e procura irá influenciar no preço final em mercados curtos de comercialização, sendo que o produto orgânico ainda não é competitivo no grande mercado.

As feiras de alimentação da produção agrícola, com venda direta ao consumidor, favorecem o fortalecimento de associações de agricultores orgânicos. Existem dificuldades, como 
a distância do local de produção aos centros consumidores, as condições das vias públicas/estradas de deslocamento do produtor até os centros urbanos, a própria habilidade para o comércio e, ainda, o tempo dedicado pelo agricultor para a venda, impactando na comercialização. De outro lado, segundo Marsden; Bancks; Bristow (2000), as cadeias curtas possibilitam ao consumidor proceder a julgamentos de valor sobre os alimentos.

As cadeias curtas são voltadas para um consumidor sensibilizado com a compra de alimentos orgânicos de produção local. As vendas diretas promovem um estreitamento com os consumidores, fidelizando cada vez mais a proposta da agricultura orgânica e sustentável. Além disso, a ausência de intermediação permite uma maior apropriação, pelos agricultores, dos resultados de seu trabalho em termos de renda (SOUSA et al., 2012).

Considerando a importância da produção e o consumo de alimentos orgânicos pela população, a presente pesquisa teve por objetivo identificar aspectos sobre a viabilidade para implantação de uma feira de alimentos orgânicos na cidade de Camaquã/RS.

\section{MATERIAIS E MÉTODOS}

A presente pesquisa foi desenvolvida na cidade de Camaquã/RS, para identificação de potencialidades para implantação de uma feira de orgânicos. Os participantes foram os produtores/feirantes que comercializam alimentos na "Feira do Produtor Rural Willi Dummer" e o gestor municipal (prefeitura).

A abordagem qualitativa foi adotada na presente pesquisa, através de entrevistas individuais com uso de roteiro próprio e questões semiestruturadas. A entrevista é considerada uma conversa com finalidade, havendo interação entre pesquisador e o sujeito. O método oferece a oportunidade de obtenção de experiências, impressões, sentimentos, percepções e opiniões dos sujeitos que participam da pesquisa (MINAYO, 2010). A fonte de dados ocorre nos contextos sociais, sendo importante haver empatia entre pesquisador e os sujeitos (MINAYO, ASSIS; SOUSA, 2005).

A entrevista individual com cada participante abordou a capacidade produtiva, os modos de produção e comercialização dos alimentos e, especificamente, sobre alimentos orgânicos. Com o representante da prefeitura, a entrevista foi conduzida a partir de questões semiestruturadas e enfocou sobre a viabilidade administrativa para implantação de uma feira de alimentos orgânicos, na cidade.

As informações coletadas com os produtores/feirantes foram anotadas em formulário próprio, à medida que os participantes iam discorrendo sobre os temas das questões. 
Posteriormente, foram agrupadas e organizadas segundo semelhança nas abordagens, para serem analisadas.

Todos os participantes concordaram em colaborar com a pesquisa, assinando o Termo de Consentimento Livre e Esclarecido. O Projeto de pesquisa foi aprovado pelo CEP/FAMED/UFPel sob número 1.805.206/2017.

\section{RESULTADOS E ANÁLISES}

A “Feira do Produtor Rural Willi Dummer", da cidade de Camaquã/RS, consiste de um modo tradicional de venda direta de frutas, verduras, alimentos oriundos de produção caseira e, ainda, de produtos de origem animal. A feira ocorre duas vezes na semana na área central da cidade, às quartas-feiras e aos sábados, das 7 h00 ao meio-dia, em prédio mantido pela prefeitura municipal. Os feirantes são responsáveis por organizá-la a cada dia de exposição, montando sua própria banca com os produtos. Ao final da atividade, cada feirante reorganiza o espaço, pois a estrutura física da feira é permanente. Portanto, ao feirante cabe zelar pelo espaço previamente estabelecido a este fim.

A organização coletiva em feira é a forma mais antiga de relacionamento comercial entre produtores e consumidores. Inicialmente, todas as feiras se realizavam associadas com festividades religiosas. A palavra latina feria em espanhol, que significa dia santo/feriado, é que deu origem à palavra feira em português (DAROLT, 2012).

As entrevistas com os participantes ocorreram no sábado pela manhã, em meio às atividades da feira. $\mathrm{O}$ entrevistador esclareceu de que se tratava de uma pesquisa sobre produção local de alimentos, porém não foi lançado diretamente o assunto alimentos orgânicos, para não influenciar nas respostas. Não houve recusa para participação na entrevista. As entrevistas ocorreram com flexibilidade, devido ao fluxo de atendimento à clientela, deixando o feirante à vontade para atender aos seus clientes e, depois retomar a entrevista.

Doze produtores rurais que atuam permanentemente da feira do produtor rural participaram da pesquisa, sendo oito homens. As idades dos entrevistados variaram entre 20 e 75 anos. Cada participante representou um único ponto de comercialização.

Todos são residentes no próprio município e os produtos comercializados são oriundos de produção local. Foi negado que houvesse produtos oriundos da central de abastecimento (CEASA). Um feirante comercializa pescados obtidos na atividade pesqueira na Lagoa dos Patos e em açudes da região. A terra (solo) destinada à agricultura é própria, menos para um. Este possui uma propriedade, mas o cultivo com vistas à comercialização ocorre em terra arrendada. 
A produção, para todos, consiste em frutas e verduras, essencialmente. Também ocorre criação de aves, bovinos, suínos. Três produtores mencionaram que também criam ovinos e peixes. Em geral, os animais são destinados ao consumo próprio e, algum excedente é levado para a comercialização.

À medida que a entrevista foi transcorrendo chegou-se à abordagem acerca de agroquímicos usados na lavoura. Sete participantes informaram sobre utilização de produtos e citaram adubo, calcário, salitre e ureia. Não mencionaram agrotóxicos. Os demais não citaram uso de qualquer substância agroquímica. Estranhamente, as respostas parecem ser inconsistentes com a realidade da produção local e com as manifestações frente a outras questões desta pesquisa. O sistema convencional é um sistema de produção agrícola tradicional no país, cujo processo de produção está baseado no emprego de adubos químicos e agrotóxicos (BOMBARDI, 2016). No momento da entrevista percebeu-se, sutilmente, haver certa confusão na distinção dos produtos usados.

O que foi observado subjetivamente no decorrer das entrevistas sugere ter havido omissão de informações sobre o uso de agrotóxicos, de modo intencional. A mídia tem propagado sobre os efeitos deletérios dos agrotóxicos e muitos consumidores estão atentos à qualidade dos produtos alimentícios, incluindo resíduos de agrotóxicos (GUIVANT, 2003). Neste caso, poderiam os participantes recear por rejeição de seus produtos cultivados por métodos convencionais? Ou, teria sido por desconhecimento e insegurança para responderem sobre a questão do uso de insumos e agrotóxicos em suas lavouras? Ou, ainda, haveria desinformação sobre a natureza dos produtos químicos usados na agricultura? Há registros de agricultores que aplicam herbicidas e similares sem orientação técnica adequada ou ainda não observam a origem do produto químico, denotando pouca importância aos riscos que correm (VIERO et al., 2016).

Geremia (2011) aponta para a carência de informações aos trabalhadores com agrotóxicos, quanto aos riscos causados à saúde humana e ao ambiente, em caso de falhas no armazenamento e na manipulação dos mesmos. Devem-se considerar as chances destes produtos tóxicos atingirem a população em geral pela contaminação de alimentos, da água e do solo.

Lamentavelmente, ocorrem diversos estímulos ao produtor para que utilize agrotóxicos, uma vez que a produtividade estará mais assegurada, concorrendo para melhores resultados e lucros (SILVA et al., 2005). O agronegócio está bastante difundido em nosso país e visa alta produtividade sendo que, em muitos casos usa plantas geneticamente modificadas e ocorrem aplicações de elevadas doses de agrotóxicos. As regiões em que predomina o agronegócio, 
principalmente de soja e cana-de-açúcar, apresentam alta concentração de agrotóxicos (BOMBARDI, 2016).

$\mathrm{Na}$ sequência das entrevistas emergiram as falas de que o uso de agrotóxicos pode causar danos à saúde. Ao serem indagados sobre problemas de saúde em suas famílias, relacionados ao uso de agrotóxicos, três participantes mencionaram casos de tontura, câncer e intoxicação.

Infelizmente, o processo produtivo agrícola brasileiro em larga escala está muito dependente dos agrotóxicos e fertilizantes químicos. Segundo Niederle; Almeida; Vezzani (2013), as práticas agrícolas tradicionais estão cada vez mais desconectadas dos processos naturais de produção alimentícia, pois valorizam a industrialização da agricultura, que por sua vez gera implicações no campo técnico e ambiental.

O dossiê da ABRASCO/2012 aponta que, na análise de amostras coletadas nas 26 Unidades Federadas do Brasil e realizada pelo Programa de Análise de Resíduos de Agrotóxicos em Alimentos (PARA) da Agência Nacional de Vigilância Sanitária (ANVISA), no ano de 2010, um terço dos alimentos consumidos cotidianamente pelos brasileiros esteve contaminado pelos agrotóxicos (RIGOTTTO et al., 2012).

Em relatório PARA/ANVISA recente, a análise de amostras de 25 alimentos de origem vegetal apresentou resíduos de agrotóxicos em mais da metade. Em 19,7\% havia concentrações acima do limite máximo de resíduos permitido. Das amostras analisadas, 18,3\% demonstraram presença de agrotóxicos não autorizados para a cultura alimentar (BRASIL, 2016).

Frente a isso, evidencia-se que o modelo de desenvolvimento econômico atual induz a modo de vida e de trabalho no campo, que ensejam graves problemas de saúde ao trabalhador do campo. A exposição dos trabalhadores aos agrotóxicos interfere na sua qualidade de vida, impactando negativamente na saúde e no meio ambiente (PESSOA; RIGOTTO, 2012).

Ao serem indagados sobre a prática de cultivo de alimentos livres de agroquímicos, todos produtores/feirantes afirmaram que o realizam. Para nove, os produtos oriundos do manejo sem pulverização de agroquímicos são destinados tanto ao consumo próprio como para comercialização. Dois deles produzem, exclusivamente, ao consumo próprio. Um afirmou que a produção livre de agrotóxicos é destinada à comercialização, fato que não foi observado por ocasião das entrevistas, como produto diferenciado dos demais.

Emerge, então, o pensamento de que os participantes realizam manejos mistos na mesma área de terra, ora com aplicação de produtos químicos, ora pelo uso de técnicas ecológicas. Sabe-se que a contaminação do solo e das fontes de água por agroquímicos é ampla, e não há ambiente adequado para produção de alimentos orgânicos nas proximidades de produção 
convencional. Um estudo realizado pela Universidade Federal de Mato Grosso sobre a contaminação da água potável e do ambiente ilustra esta afirmação. Trata-se de o acidente rural ampliado decorrente da pulverização de agrotóxicos em lavoura de soja transgênica, em 2006, no município de Lucas do Rio Verde/MT, atingindo a zona urbana. A contaminação ocasionou danos em plantas medicinais cultivadas na região central da cidade e em hortaliças em 65 chácaras do entorno da cidade. A contaminação desencadeou um surto de intoxicações agudas em crianças e idosos (PIGNATI; MACHADO; CABRAL, 2007).

O sistema orgânico é uma metodologia de produção agrícola que dispensa o uso de insumos químicos e se caracteriza por um processo que leva em conta a relação solo/planta/ambiente com o intuito de preservar o meio ambiente, a saúde dos homens e dos animais (BRASIL, 2005).

Todos os produtores/feirantes, ao serem indagados sobre interesse pessoal em produzir alimentos orgânicos para fins de comercialização, responderam afirmativamente. Eles também afirmaram que há possibilidades de lucratividade com este tipo de produção, o que poderia ser mais um incentivo na adoção pela agroecologia. Em um estudo com produtores de orgânicos em Espírito Santo, os aspectos positivos para saúde e ambiente foram valorizados. Porém, os produtores apontaram para fortes desafios quanto o retorno financeiro deste tipo de agricultura (LOSS; FOEGER, 2009).

Atualmente, cerca de $80 \%$ dos alimentos orgânicos consumidos no Brasil são oriundos de estabelecimentos agropecuários orgânicos, inserido na categoria agricultura familiar. A agricultura orgânica requer certificações, o que a grande maioria não apresenta. Isto é considerado um grande desafio aos pequenos produtores, que precisam se organizar para inovar quanto às exigências de certificação (MAZZOLENI; OLIVEIRA, 2010; LOURENÇO, SCHNEIDER, GAZOLLA, 2017).

O estudo conduzido por Silva Jr et al. (2014), em uma análise comparativa sobre os dois métodos de produção de morango, orgânico e convencional, na cidade de Rancho Queimado/SC, constatou que o método orgânico foi economicamente mais rentável. O morango orgânico alcançou um valor médio de comercialização três vezes maior que o convencional, levando em conta a valorização do produto no mercado.

Ao serem indagados se acreditavam em futura viabilidade de instalação de uma feira exclusiva para alimentos orgânicos, em Camaquã/RS, todos os participantes se manifestaram afirmativamente. E, em caso desta se concretizar realmente, o interesse em participar como feirante de orgânicos foi unânime. 
As vendas diretas pelo método face-a-face de produtor e consumidor, como acontecem em feiras do produtor, são propostas eficazes para fortalecimento das associações de agricultores orgânicos. Este tipo de comercialização promove um estreitamento com os consumidores, fidelizando cada vez mais a proposta da agricultura orgânica e sustentável. A ausência de intermediação permite aos agricultores obterem melhores resultados de seu trabalho, em termos de renda (SOUSA et al., 2012). As dificuldades dadas pelas distâncias a serem percorridas, do local da produção até os centros consumidores, as questões climáticas e os entraves que ocorrem na venda direta do produtor em feiras precisam ser ultrapassadas para a ampliação de novos mercados (idem).

O Brasil é o país com destaque no consumo de produtos orgânicos dentro da América Latina. O mercado cresce firmemente, resultado da percepção dos consumidores sobre a qualidade do produto orgânico em relação ao convencional, dos benefícios para a sua saúde e para o meio-ambiente (GUIVANT, 2003). O Brasil tem condições de clima e de solo que possibilitam produzir ampla gama de produtos orgânicos, além de ter uma grande área agrícola de cultivo diversificado (NODARI; GUERRA, 2015).

A sazonalidade de produtos agrícolas oferecidos à população sofre influência direta de fatores ambientais, sendo que as variações entre as estações do ano contribuem para com a maior diversidade alimentar. Os preços de comercialização são autorregulados pelo mercado, dados pela oferta e procura.

Muitas características comportamentais de consumidores de diversos países, que frequentam feiras de hortifrutigranjeiros, são semelhantes entre si. Em Portugal, foi observado que a escolha dos alimentos por idosos era influenciada pela oferta a preços mais acessíveis e, em local de venda próximo de suas residências. Os consumidores de baixa renda tendem a escolher os alimentos a partir de sabor e preço, não observando o seu valor nutricional (ANDRÉ, 2013). Os consumidores urbanos de melhor nível educacional e econômico, ao optarem por alimentos orgânicos, o fazem por se tratarem de alimentos saudáveis, que respeitam o ambiente, a ética e a identidade de ser orgânico. A localização da produção é um elemento chave para gerar sentimento de confiança sobre esta produção, junto aos consumidores, afirma Kearney (2010).

Assim, a instalação de uma feira de orgânicos é complexa, requerendo afinidade entre potencialidades e interesses do produtor local com os recursos e desejos da comunidade de consumidores.

$\mathrm{Na}$ entrevista com representante da prefeitura, participou um membro de gestão da Secretaria Municipal de Agricultura. Segundo o participante, ocorre produção de alimentos orgânicos no município e, a prefeitura apoia este tipo de agricultura através de projetos de 
fortalecimento das associações de produtores de hortifrutigranjeiros. Porém, a fala não foi devidamente esclarecedora de como ocorrem os referidos projetos aos agricultores locais e, particularmente, em produção orgânica. Manifestou-se favorável à instalação de uma feira para comercialização de produtos orgânicos, no município. E, afirmou que poderia ser concedido espaço público para tal, além da colaboração da prefeitura na acreditação técnica da mesma.

Por ocasião dessa entrevista, percebeu-se certo desconhecimento sobre a distinção entre os modos de cultivo convencional e orgânico. Do mesmo modo que os produtores/feirantes, o participante manifestou-se favorável à convivência de ambos os modos de produção em um mesmo espaço de produção e comercialização.

Sendo assim, é necessário ampliar as informações aos setores públicos envolvidos com produção agrícola e, aos feirantes esclarecer que, sob princípios agroecológicos, a produção de alimentos orgânicos é ímpar (ALMEIDA, 2002; LOSS; FOEGER, 2009).

Para o representante da prefeitura, a comercialização dos alimentos orgânicos concomitantemente aos produtos convencionais, possibilitaria o aproveitamento do mesmo espaço físico destinado à feira do produtor local. No entanto, considera-se inadequada esta possibilidade, pois mesmo sendo produtos semelhantes, são oriundos de modos de cultivo diferentes e não podem competir entre si, em um patamar comercial. Os consumidores necessitam de informações esclarecedoras sobre a qualidade e os valores dos orgânicos, favorecendo a adoção em sua alimentação. Se houver associação entre produtos convencionais e orgânicos em uma feira, a insegurança entre os consumidores poderá emergir. Assim, valoriza-se a comercialização de alimentos oriundos de manejo agroecológico ocorrendo em feiras exclusivas para tal.

\section{CONSIDERAÇÕES FINAIS}

O município apresenta capacidade produtiva para agricultura familiar, possui feira ativa de alimentos oriundos de cultivo convencional e, a comunidade camaquense está habituada a aquisição de hortifrutigranjeiros pela venda direta. Atualmente, não ocorre produção de alimentos orgânicos voltados à comercialização, havendo clara manifestação de interesse pelos produtores locais e feirantes, em cultivar alimentos de natureza orgânica.

Sendo que os produtores/feirantes necessitam de esclarecimentos sobre os modos de produção, comercialização, certificações e garantias previstas em sistemas agroecológicos, a presença do poder público é essencial. Observou-se que ocorre relevante distanciamento do poder público quanto às questões dos orgânicos, no município. No futuro, caso venha ocorrer 
Indicativos para implantação de uma feira orgânica em Camaquã/RS

produção de orgânicos suficientes para comercialização, recomenda-se a instalação de uma feira exclusiva, visto as características agroecológicas de produção serem distintas das convencionais.

No momento atual, considerando as informações encontradas, a implantação de uma feira de alimentos orgânicos na comunidade de Camaquã/RS não seria realizável. A produção local de orgânicos apresenta-se insuficiente, faltam estímulos para a adoção de métodos agroecológicos e há carência de incentivos pelo poder público.

Sugere-se a implantação de um canal de divulgação e esclarecimentos sobre o valor dos alimentos orgânicos para a saúde da população e o ambiente. O gestor municipal aponta disposição para alçar novos horizontes junto aos produtores locais, para acreditação e implantação da feira de alimentos orgânicos. Mas, será necessário organizar meios para que agricultores sejam capacitados e obtenham condições técnicas para a produção de alimentos, segundo os princípios agroecológicos.

\section{REFERÊNCIAS}

ALMEIDA, Jalcione. Agroecologia: paradigma para tempos futuros resistência para o tempo presente? Desenvolvimento e Meio Ambiente, Curitiba, n.6, p. 29-40, jul./dez. 2002.

ALTIERI, M.; NICHOLLS, C. Agroecology and the search for a truly sustainable agriculture. México: PNUMA, 2005.

ANDRÉ, Ana Isabel Neves Ferreira. Sazonalidade e Alimentação: influência da sazonalidade nos hábitos alimentares. 2013. 132f. Dissertação (Mestrado em Ciências da Nutrição) - Faculdade de Ciências da Nutrição e Alimentação, Universidade do Porto, Portugal, 2013. Disponível em:

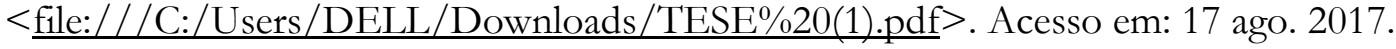

AZEVEDO E.; PELICIONI, M. C. F. Promoção da Saúde, Sustentabilidade e Agroecologia: uma discussão intersetorial. Saudesoc., São Paulo, v. 20, n. 3, p. 715-729, jul./set. 2011.

AZEVEDO, E. Alimentos orgânicos: ampliando conceitos de saúde humana, ambiental e social. Tubarão: Ed. Unisul, 2006, p. 386.

BOMBARDI, Larissa. Pequeno ensaio cartográfico sobre o uso de agrotóxicos no Brasil. São Paulo: Blurb, 2016.

BRASIL. Ministério da Agricultura Pecuária e Abastecimento. Secretaria de Desenvolvimento Agropecuário e Cooperativismo. Produtos orgânicos: o olho do consumidor. Brasília/DF, MAPA/ACS, 2009. 34p.

BRASIL. Ministério da Saúde. Agência Nacional de Vigilância Sanitária. Programa de Análise de Resíduo de Agrotóxico em Alimentos- PARA Relatório de atividades de 2013 a 2015. Brasília, DF: ANVISA, nov.2016. Disponível em: $<$ http://portal.anvisa.gov.br/documents/111215/0/Relat $\%$ C3\%B3rio+PARA+2013- 
Indicativos para implantação de uma feira orgânica em Camaquã/RS

2015 VERS $\% C 3 \% 83$ O-FINAL.pdf/494cd7c5-5408-4e6a-b0e5-5098cbf759f8>. Acesso em: 19 mar. 2017.

BRASIL. Ministério do Desenvolvimento Agrário. MEIRELLES, L.R; RUPP, L.C.D. (Coord.). Agricultura Ecológica: princípios básicos. Mar. 2005. Disponível em:

$<$ http://www.centroecologico.org.br/Agricultura Ecologica/Cartilha Agricultura Ecologica.pd f >. Acesso em: 19 mar. 2016.

CAMAQUÃ. História do Município. Disponível em: < http://www.camaqua.rs.gov.br/>. Acesso em: 17 jun. 2016.

CAPORAL, Francisco Roberto; COSTABEBER, José Antônio. Agroecologia e desenvolvimento rural sustentável: perspectivas para uma nova extensão rural. Porto Alegre: EMATER/RS-ASCAR, 2004.

DAROLT, M. R. Conexão ecológica: novas relações entre agricultores e consumidores. Londrina, IAPAR, 2012. 162 p.

FOOD AND AGRICULTURE ORGANIZATION (FAO). Organic Agriculture. Fifteen Session of the Committee on Agriculture, 1999. Disponível em:

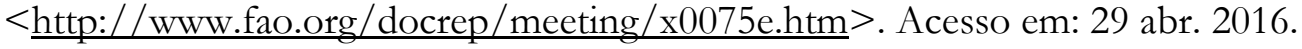

GEREMIA, Barbara. Agrotóxicos: o emprego indiscriminado de produtos químicos no ambiente de trabalho rural e a responsabilização por danos à saúde. 2011.142f. Dissertação (Mestrado em Direito). Faculdade de Direito, Universidade de Caxias do Sul, Caxias do Sul, 2011. Disponível em:

$<$ https://repositorio.ucs.br/xmlui/bitstream/handle/11338/600/Dissertacao $\% 20$ Barbara $\% 20 \mathrm{G}$ eremia.pdf>. Acesso em: 20 maio 2017.

GUIVANT, Julia S. Os supermercados na oferta de alimentos orgânicos: apelando ao estilo de vida ego-trip. Ambient. Soc., Campinas, v. 6, n. 2, p. 63-81, dez. 2003.

INSTITUTO BRASILEIRO DE GEOGRAFIA E ESTATÍSTICA (IBGE). Censo

Agropecuário/2006. Rio de Janeiro: IBGE; 2006. Disponível em:

< https://ww2.ibge.gov.br/home/estatistica/economia/agropecuaria/censoagro/2006 segunda apuracao/default.shtm> Acesso em: 01 ago. 2017.

KEARNEY, John. Food consumption trends and drivers. Phil. Trans. R. Soc. B. 16 aug. 2010. Disponível em: < http://rstb.royalsocietypublishing.org/content/365/1554/2793 > . Acesso em: 01 jul. 2017.

LIMA, Elinete Eliete de. Alimentos orgânicos na alimentação escolar pública catarinense: um estudo de caso. 2006. 128f. Dissertação (Mestrado em Nutrição)- Faculdade de Nutrição, Universidade Federal de Santa Catarina, Florianópolis, 2006. Disponível em:

$<$ https://repositorio.ufsc.br/handle/123456789/88712>. Acesso em: 15 mar. 2017.

LOSS, A. T. G.; FOEGER, M. J. Benefícios e desafios da agricultura orgânica nas pequenas propriedades rurais de Santa Teresa, ES: um estudo de caso. Rev. Bras.de Agroecologia, Porto Alegre, v. 4, n. 2, p. 530-534, nov.2009. Disponível em:

$<$ http:/ $/$ www.scielosp.org/scielo.php? script $=$ sci nlinks\&ref $=000169 \& p i d=S 0104$ 1290201100030001600034\&lng=en>. Acesso em: 01 ago. 2017. 
LOURENÇO, Vigolo Andréia; SCHNEIDER, Sergio; GAZOLLA, Márcio. A agricultura orgânica no Brasil: um perfil a partir do censo agropecuário 2006. Extensão Rural, Santa Maria, v.24, n.1, p.42-61, jan./mar. 2017.

MARSDEN, Terry; BANCKS Jo; BRISTOW, Gilian. Food Supply Chain Approaches: exploring their role in rural development. Sociologia Ruralis, v.40, p.424- 435, out. 2000.

MAZZOLENI, Eduardo Mello; OLIVEIRA, Luiz Guilherme de. Inovação tecnológica na agricultura orgânica: estudo de caso da certificação do processamento pós-colheita. Rev. Econ. Sociol. Rural, Piracicaba/SP, v.48, n.3, p. 567-586, jul./set. 2010.

MINAYO, M.C.S.; ASSIS, S.G.; SOUZA, E. R (org). Avaliação por triangulação de métodos: abordagem de programas sociais. Rio de Janeiro: FIOCRUZ, 2005.

MINAYO, Maria Cecília de S. O desafio do conhecimento: pesquisa qualitativa em saúde. 7.ed. São Paulo, Hucitec, 2010.

NIEDERLE, Paulo André; ALMEIDA, Luciano de; VEZZANI, Fabiane Machado. Agroecologia: práticas, mercados e políticas para uma nova agricultura. Curitiba: Kairós, 2013.

NODARI, Rubens Onofre; GUERRA, Miguel Pedro. A agroecologia: estratégias de pesquisa e valores. Estud. av., São Paulo, v.29, n.83, p.183-207, 2015.

PESSOA, Vanira Matos; RIGOTTO, Raquel Maria. Agronegócio: geração de desigualdades sociais, impactos no modo de vida e novas necessidades de saúde nos trabalhadores rurais. Rev. bras. Saúde ocup., São Paulo, v. 37, n. 125, p. 65-77, jun. 2012. Disponível em: $<$ http://www.scielo.br/scielo.php?script=sci arttext\&pid=S030376572012000100010\&lng=en\&nrm=iso >. Acesso em: 01 jun. 2016.

PIGNATI, Wanderlei Antonio; MACHADO, Jorge M. H.; CABRAL, James F. Acidente rural ampliado: o caso das "chuvas" de agrotóxicos sobre a cidade de Lucas do RioVerde/ MT. Ciênc. Saúde coletiva, Rio de Janeiro, v. 12, n. 1, p.105-114, mar. 2007.

RIGOTTO, R.M.; PORTO M.F.; FOLGADO, C.; FARIA, N.M; AUGUSTO, L.G.S; BEDOR, C.; BURIGO, A; CARNEIRO, F.F; CASTRO, F.P; FERNANDES, G.B; FERREIRA, M.J.M; FRIEDRICH, K; MARINHO, A.M.C.P; MONTEIRO, D; PIGNATTI, W; PINHEIRO, T.M.M; RIZZOLO, A; SILVA, N; TYGEL, A. Dossiê ABRASCO - Um alerta sobre os impactos dos Agrotóxicos na Saúde. Parte 3 - Agrotóxicos, conhecimento científico e popular: construindo a ecologia de saberes. Porto Alegre, nov. 2012. Disponível em: $<$ http://www.contraosagrotoxicos.org/index.php/materiais/relatorios/dossie-abrasco-umalerta-sobre-os-impactos-dos-agrotoxicos-na-saude-parte-3/download $>$. Acesso em: 30 maio 2017.

SILVA JUNIOR, P. B.; SOUZA, P.; SOUZA, R.; LUNKES, R. J. Estudo comparativo entre agricultura orgânica e convencional no cultivo de morango em Rancho Queimado/SC. Revista Ibero-Americana de Ciências Ambientais, Aquidabã, v.5, n.1, p.115-128, 2014.

SILVA, Jandira Maciel da; NOVATO-SILVA, Eliane; FARIA, Horácio Pereira; PINHEIRO, Tarcísio Márcio Magalhães. Agrotóxico e trabalho: uma combinação perigosa para a saúde do trabalhador rural. Ciênc. saúde coletiva, Rio de Janeiro, v.10, n.4, p.891-903, dez. 2005. 
Indicativos para implantação de uma feira orgânica em Camaquã/RS

SOUSA, A. A.; AZEVEDO, E.; LIMA, E. E.; SILVA, A. P. F. Alimentos orgânicos e saúde humana: estudo sobre as controvérsias. Rev Panam Salud Publica, v, 31, n. 6, p. 513-517, 2012.

VIERO, Cibelle Mello; CAMPONOGARA, Silviamar; CEZAR-VAZ, Marta Regina; COSTA, Valdecir Zavarese da; BECK, Carmem Lúcia Colomé. Sociedade de risco: o uso dos agrotóxicos e implicações na saúde do trabalhador rural. Esc. Anna Nery, Rio de Janeiro, v.20, n.1, p.99-105, mar. 2016.

Recebido em: 20/11/2017

Aceito em: 28/06/2018 